\title{
Concept term repurposing: Framing shifts in domains and terminology
}

Author contact information:

Laura Ridenour

University of Wisconsin-Milwaukee

ridenour@uwm.edu

\section{Introduction}

As language is our primary means of communication, the words we choose to use are critical to conveying meaning. Dahlberg (2006) explains how knowledge can be shared by means of language through space and time. Time, space, and educational background can all play parts in a loss of intended meaning. Shared conceptualizations between domains may be represented by different terminology, but when the concepts align and are used to communicate across multiple disciplines, they are referred to as boundary objects (Bowker and Star 1999).

Disciplines evolve, and new disciplines are formed as science and our understanding of the universe change and new knowledge is produced (Zhang and Jacob 2013). Understanding how disciplines form and select terminology to reflect shared epistemological stances and nuanced understandings of new concepts requires domain knowledge. The way in which we communicate our understanding of knowledge we have created is in both language and symbology, but information systems do not allow for the mutability and evolution of language without human intervention (Tennis 2002). Repurposing concept terms from other disciplines may aid in understanding of the implications of newly described concepts in new fields, but may also cause concept ambiguity for both humans and information systems. In this paper, I explore the relationship between disciplinary formation, human understanding, and terminology. Pieces cited in this paper are classic to the foundations of knowledge organization (KO). Contributing a theoretical framework for understanding how these three pieces of the communication puzzle are formed will create a basis on which to study the phenomenon of the creation and reuse of concept terms.

\section{Domains, Growth, and Epistemological Stances}

In $\mathrm{KO}$, a domain is most succinctly defined as "a group with an ontological base that reveals an underlying teleology, a set of common hypotheses, epistemological consensus on methodological approaches, and social semantics" (Smiraglia 2012, 114). The defining features of domains have been and are sometimes debated, but groups we might call domains, invisible colleges, or discourse communities require social networking to glue the groups together even though the types of interactions between the groups are different (Smiraglia 2012). Domains are analyzed and defined by their intension, or granularity, and their extension, or coverage of space, time, and topic. Zhang and Jacob (2013) discuss how changes in information environments alter the dimensions that physical, epistemological, and virtual boundaries span, and how they can be crossed. Exploring methods of harmonizing scientific terminology by identifying boundary objects and creating ways to span boundaries will allow for furthering scientific discoveries through increased ease of research. Choices in classification reflect the epistemological stances of disciplines, and affect the interoperability of categorization across domains. Domains establish their own argot, which provides a means of analyzing their unique epistemological standpoints and origins from the point in time which they are analyzed. 
Communication in domains can be understood by going back to the roots of symbology and semiology. Saussure's dichotomy of signed and signer provide an iterative structure paralleling Peirce's representation, object, and identifier (ROI), that are used by both the sender and receiver of a message (Saussure 1959; Peirce Edition Project, Nathan Houser [et al.] 1992). This iterative process of understanding is related to Shannon and Weaver's model of communication, where noise introduced into a channel distorts the meaning of the original message (Shannon 1948). Noise introduced into a representation by the nature of individual knowledge assimilation and understanding distorts the meaning of language-represented knowledge; furthermore, introducing new concepts into a domain has potential to distort the intended meaning by adjusting the language used to encode these concepts. Combining this with the inherent temporal nature of language, ideas encoded into symbolic form must be decoded with an understanding of the context in which they were formulated. Star $(2010,602)$ notes that boundary objects occupy a shared space, and the commonly shared objects form the boundaries between domains and require "interpretive flexibility" to address different viewpoints between communities. Figure 1 illustrates the adoption of a repurposed concept word into a research area. A dashed line is used for the transplantation of the word into the new context, as the meaning of the word sign is mutable, and it will not be identical to its original meaning. Instead, it transposes meaning from the original context, requiring flexibility on the part of the community in which the new phenomenon is introduced.

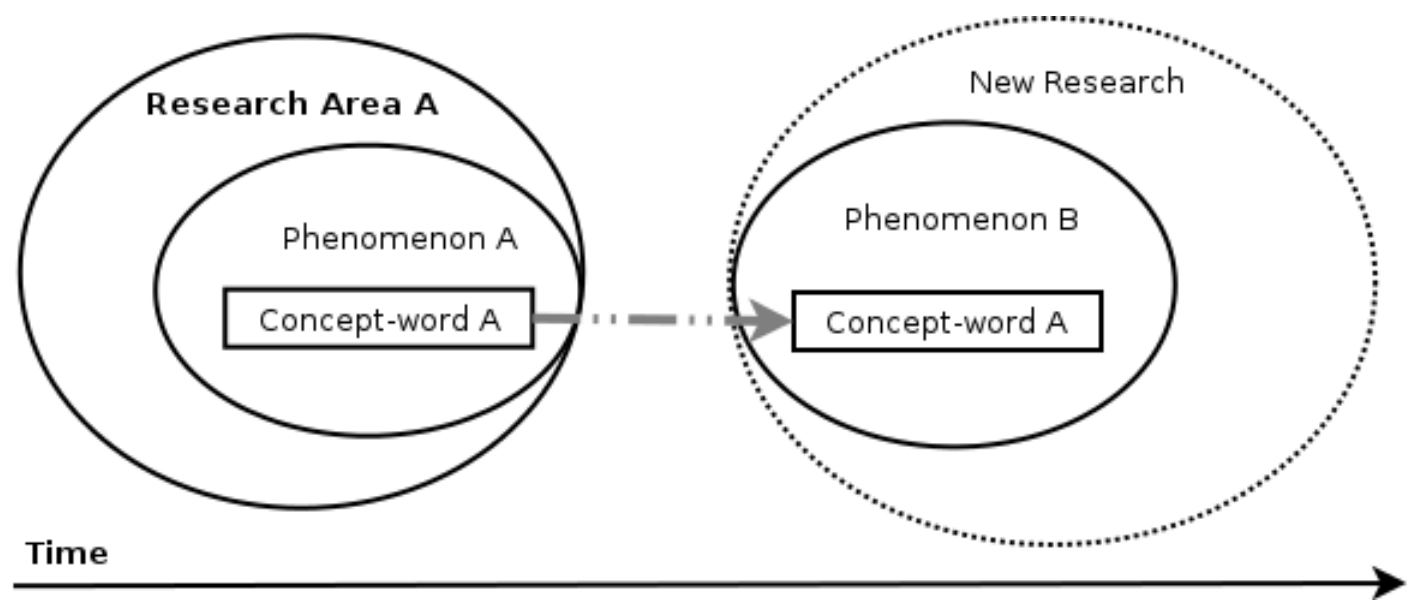

Figure 1: Borrowed concept words from an established domain

Domains shift over time, and this can be modeled and explained in multiple ways (Figure 2). According to Wilson (1993), communication breakdowns occur between specialties, not between individual researchers. Information from outside of a specialty is not considered to be as pertinent when used in support of a hypothesis inside of most domains. Wilson's view complements Kuhn's view of scientific paradigms and paradigmatic shift, but does not propose a solution for breakdowns in cross-disciplinary communication (Wilson 1993; Kuhn 1962). Borrowing paradigms from other disciplines encourages the adoption of language used, but others within a discipline may not seriously regard such borrowed terminology (Wilson 1993). Habermas $(1989,242)$ framed the acceptability of a speech act as pragmatic; a speaker creates a speech act to appeal to the truth as viewed by the audience for which the speech act is intended. Here speakers draw on their "reservoirs of potential reasons" to support their claims, and the truth of the speech act is determined by the acceptability of the reasons speakers provide to their 
intended audiences. Assuming Wilson's stance that communications occur between specialties, a researcher crafting a statement whose validity is to be assessed by an audience who prefers specific terms, the truth of the researcher's statement will be validated against the truths held by that audience. Popper (1979) proposed a trichotomous view of the universe in which each level, or "world," is capable of interacting with the other levels. World 1 consists of physical objects and tangible forces. World 2 consists of the internalized knowledge and private thought processes, and World 3 encompasses the partially autonomous realm of objective knowledge, which includes products of human thought that are shared publicly (Popper 1979). Considering all of this, reusing terminology from other disciplines may raise questions of the validity of arguments when considering the ability of the individual to understand and reproduce science if it is to be considered objective (Popper 2002, 44).

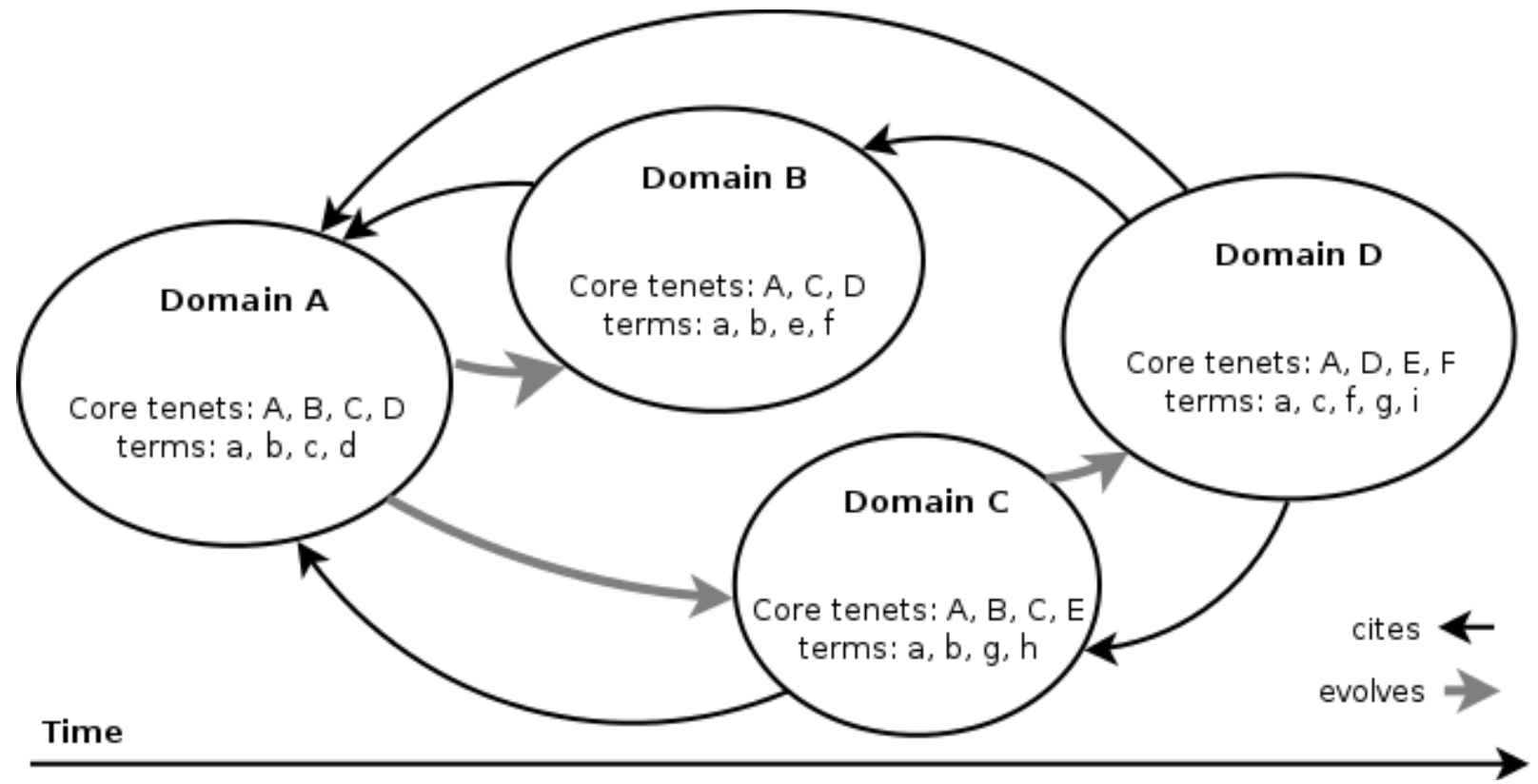

Figure 2: Hypothetical model of domains evolving into new domains and adopting terms over time

\section{Discussion}

A new discipline inherits traits and terminology from the disciplines from which its members receive education. Should a new discipline follow Kuhn's paradigm and emerge from another already-established discipline, we would expect the vocabulary from the newly established discipline to be heavily influenced by its parent disciplines, and for members of the new research specialty to produce a corpus of knowledge that similarly cites its parent disciplines, as well as education within the parent discipline or an allied field. Members of a new discipline and have experiences that would build a lens to interpret the world that was subjectively built by their education, following Husserl's idea of intersubjectivity (1950). His process of "empathy" allows the researchers to use their imaginations to build bridges of understanding when encountering new concepts.

New disciplines may also adopt terms associated with existing concepts from other fields, which demonstrates Saussure's dichotomous and mutable relationship between the signified and 
the signifier (Saussure 1959). Examples of concept term repurposing can be found in many disciplines, but we will discuss two found in information science. Tennis (2002) uses the term "ontogeny," to describe how the reader's association with a pre-existing linguistic sign cues the reader to the biological origins of the concept relating to growth, change, and establishment of an organism. Kozak (2013) applied the legal term "home rule" to describe the phenomenon of Albertan municipalities creating independent internet systems. Historical precedence for the term was found in both the British Isles and the US; in the US, it describes the granting of the right to municipalities to govern themselves by state governments. Bates' (1989) "berrypicking" model of information retrieval draws upon the reader's understanding of the hunt for ripe berries, which requires a process of internal questioning, and flags the reader's understanding of what is required when picking berries. A similar conceptual analogy found in the allied discipline of telecommunications, known as "cherry picking" (Graham and Marvin 1994), describes the process of companies finding and keeping the best customers to maximize profits. Both berrypicking and cherry picking describe processes involving locating and keeping the most choice morsels in a search of some sort.

While using the sign to bridge the meaning between an old concept and a new concept, the introduction of a new meaning associated with the sign creates ambiguity for humans and machines; given inadequate background knowledge, sufficient context is required in order to interpret the repurposed term in question. Humans require context to glean meaning from ambiguous language (Piantadosi, Tily, and Gibson 2012), which may be afforded by understanding the etymology of a concept-word if a parallel meaning is not immediately intuitively available.

The more formalized a discipline, the more self-similar the information seeking habits of members of the discipline (Hjørland 1997). Ill-defined disciplines (Hjørland 1997, 138) may lack a sufficiently developed enough terminology on which to base a controlled vocabulary that would be used to identify documents relevant to the discipline. A lack of agreed-upon terminology may reflect not only a new discipline, but a new area of interdisciplinarity. Using Smiraglia's (2012) outline for the functional parameters of domains, discourse communities, and invisible colleges, the features attributed to the communication channels of each must be taken into consideration when examining their discourse.

\section{Conclusion}

This piece was framed using Husserl's phenomenological stance citing pieces classic to KO. Representing theories as information in text requires a culturally-dependent and contextually accepted understanding of the concept-signs used (Foucault 1970, 46-47). As representation is not based on the inherent character of reality, classification is arbitrary in nature. We experience knowledge as our own, individually synthesized reality, which is informed by that which we have experienced and perceive (Husserl 1950). In the context of science, our individual interpretations are based on our previous perceptions and experiences of science. Practically speaking, our perceptions of the realities we perceive must be reflected in mutually shared language in discourse. 


\section{Works Cited}

Bates, Marcia J. 1989. "The Design of Browsing and Berrypicking Techniques for the Online Search Interface." Online Review 13 (5): 407-24.

Bowker, Geoffrey C., and Susan Leigh Star. 1999. Sorting Things out: Classification and Its Consequences. MIT Press.

Dahlberg, Ingetraut. 2006. "Knowledge Organization: A New Science?” Knowledge Organization 33 (1): 11-19.

Foucault, Michel. 1970. The Order of Things: An Archaeology of the Human Sciences. London: Routledge.

Graham, Stephen, and Simon Marvin. 1994. "Cherry Picking and Social Dumping: Utilities in the 1990's." Utilities Policy 4 (2): 113-19.

Habermas, Jürgen. 1998. "Actions, Speech Acts, Linguistically Mediated Interactions, and the Lifeworld (1998)." In On the Pragmatics of Communication, edited by Maeve Cooke, 216-55. Studies in Contemporary German Social Thought. Massachusetts Institute of Technology.

Hjørland, Birger. 1997. Information Seeking and Subject Representation: An Activity-Theoretical Approach to Information Science. New Directions in Information Management 34. Westport, Connecticut: Greenwood Press.

Husserl, Edmund. 1950. Cartesian Meditations: An Introduction to Phenomenology. Translated by Dorion Cairns. Boston: Kluwer Academic Publishers.

Kozak, Nadine. 2013. "Local Communities and Home Rule: Extending the Alberta SuperNet to Unserved Areas." The Journal of Community Informatics 10 (2). http://cijournal.net/index.php/ciej/article/view/1002/1087.

Kuhn, Thomas S. 1962. The Structure of Scientific Revolutions. Chicago: University of Chicago press.

Peirce Edition Project, Nathan Houser [et al.], ed. 1992. The Essential Peirce: Selected Philosophical Writings. Vol. 2 (1893-1913). 2 vols. Bloomington: Indiana University Press.

Piantadosi, Steven T., Harry Tily, and Edward Gibson. 2012. "The Communicative Function of Ambiguity in Language." Cognition 122 (3): 280-91. doi:10.1016/j.cognition.2011.10.004.

Popper, Karl. 1979. “Three Worlds.” Ann Arbor, Michigan. https://www.theeonline.com/Documents/Popper-3Worlds.pdf.

- 2002. The Logic of Scientific Discoveries. Routledge Classics. London; New York: Routledge.

Saussure, Ferdinand de. 1959. Course in General Linguistics. Edited by Charles Bally, Albert Sechehaye, and Albert Reidlinger. Translated by Wade Baskin. New York: McGraw Hill.

Shannon, Claude E. 1948. "A Mathematical Theory of Communication, Part I." Bell Systems Technical Journal, no. 27: 379-423.

Smiraglia, Richard P. 2012. "Epistemology of Domain Analysis." In Cultural Frames of Knowledge, edited by Richard P. Smiraglia and Hur-li Lee, 111-24. Ergon.

Star, Susan Leigh. 2010. "This Is Not a Boundary Object: Reflections on the Origin of a Concept." Science, Technology \& Human Values 35 (5): 601-17.

Tennis, Joseph. 2002. "Subject Ontogeny: Subject Access through Time and the Dimensionality of Classification." ADVANCES IN KNOWLEDGE ORGANIZATION 8: 54-59. 
Wilson, Patrick. 1993. "Communication Efficiency in Research and Development." Journal of the American Society for Information Science 44: 376-82.

Zhang, Guo, and Elin K. Jacob. 2013. "Understanding Boundaries: Physical, Epistemological and Virtual Dimensions." Information Research 18 (3). 